\title{
BMJ Open Support for smoke-free policy among Malaysian adults: findings from a population-based study
}

\author{
Lim Kuang Hock, ${ }^{1}$ Lim Hui Li, ${ }^{2}$ Teh Chien Huey, ${ }^{1}$ Veloo Yuvaneswary, ${ }^{1}$ Pan Sayan, ${ }^{3}$ \\ Muhammad Fadhli Muhd Yusoff, ${ }^{3}$ Lim Kuang Kuay, ${ }^{3}$ Ling Miaw Yn, ${ }^{3}$ \\ Cheong Kee Chee, ${ }^{1}$ Ghazali Sumarni Mohd ${ }^{1}$
}

To cite: Kuang Hock L, Hui Li L, Chien Huey T, et al. Support for smoke-free policy among Malaysian adults: findings from a populationbased study. BMJ Open 2019;9:e020304. doi:10.1136/ bmjopen-2017-020304

- Prepublication history for this paper is available online. To view these files, please visit the journal online (http://dx.doi org/10.1136/bmjopen-2017020304).

Received 28 0ctober 2017 Revised 23 October 2018 Accepted 26 October 2018

Check for updates

(c) Author(s) (or their employer(s)) 2019. Re-use permitted under CC BY-NC. No commercial re-use. See rights and permissions. Published by BMJ.

${ }^{1}$ Institute for Medical Research, Kuala Lumpur, Malaysia

${ }^{2}$ Hospital Sultan Haji Ahmad

Shah, Mentakab, Pahang,

Malaysia

${ }^{3}$ Institute of Public Health, Kuala Lumpur, Malaysia

Correspondence to

Mr Lim Kuang Hock;

keelimkota@yahoo.com

\section{ABSTRACT}

Objective Public opinion and support can be powerful mandates for smoke-free policy. However, the scarcity of evidence on public opinion among Malaysians necessitates further investigation. Therefore, this study aimed to determine the level of support for smoke-free policy at various public domains and its associated factors among Malaysian adults.

Design Data were derived from the Global Adult Tobacco Survey, Malaysia (GATS-M). GATS-M is a nationwide study that employed a multistage, proportionate-to-size sampling strategy to select a representative sample of 5112 Malaysian adults aged 15 years and above. Multiple logistic regression was used to identify factors associated with support for smoke-free policy in selected public domains that is, workplaces, restaurants, bars, hotels, casinos, karaoke centres, public transport terminals and shopping centres.

Results The level of support for enactment of a smokefree policy at selected public domains varied from $37.8 \%$ to $94.4 \%$, with the highest support was for gazetted smoke-free domains, namely, shopping centres $(94.4 \%$, $95 \% \mathrm{Cl}: 93.2 \%$ to $95.3 \%$ ) and public transport terminals (85.2\%, 95\% Cl: 83.3\% to 86.9\%). Multiple logistic regression revealed that non-smokers were more likely to support smoke-free policy at all domains. In addition, respondents who worked in workplaces with total or partial smoking restrictions were more likely to support a smoke-free policy ((total restriction adjusted OR (AOR): 14.94 (6.44 to 34.64); partial restriction AOR: 2.96 (1.138 to 6.35); non-restriction was applied as a reference). Conclusion A majority of the Malaysian adult population supported the smoke-free policy, especially at gazetted smoke-free domains. Therefore, expansion of a total smoking ban to workplaces, restaurants, bars, hotels, casinos and karaoke centres is strongly recommended to reduce exposure to secondhand smoke and to denormalise smoking behaviour.

\section{INTRODUCTION}

Studies have shown that exposure to secondhand smoke (SHS) increases the risk of developing respiratory symptoms, ${ }^{1}$ lung cancer, ${ }^{2}$ acute coronary syndromes ${ }^{2} 4$ and stroke. ${ }^{25}$ Globally, 603000 premature deaths

\section{Strengths and limitations of the study}

- Representativeness and sample size adequacy as well as high response rate enable generalisation of findings to the Malaysian population.

- Data were collected through face-to-face interview, ensuring the quality of the data.

- Exposure to secondhand smoke among the non-smokers was not measured objectively via determination of carbon monoxide level in expired air or serum cotinine but from self-report.

- Investigated support for enactment of smoke-free policy at a few selected public domains only.

attributable to SHS-related diseases were reported in 2004, ${ }^{2}$ In 2011, the Global Adult Tobacco Survey, Malaysia (GATS-M) revealed that $39.8 \%$ and $38.4 \%$ of adults were exposed to SHS in indoor workplaces or at home, respectively. And among those who visited public areas such as cafes, coffee shops, bistros, bars and nightclubs, restaurants, government buildings, indoor shopping complexes and healthcare facilities in the last 30 days, $84.9 \%$ of them reported exposure to SHS in cafes/coffee shops/bistros, $78.7 \%$ in bar/nightclubs, $71 \%$ in restaurants, $28.2 \%$ in government buildings, $13.6 \%$ in indoor shopping complexes and $8.7 \%$ in healthcare facilities. Such SHS exposure rates warrant due attention as higher rates of SHS exposure could lead to higher incidences of tobacco related-diseases which will ultimately increase the burden of SHS-related disease ${ }^{6}$ among the Malaysian population.

Acknowledging the risks of SHS exposure as well as the effectiveness of prohibiting smoking in public areas to reduce exposure to $\mathrm{SHS},{ }^{7-11}$ the Malaysian government, through the Ministry of Health, has adopted a number of measures pertaining to smoking bans. For instance, the Control of Tobacco Products Regulation (CTPR) was introduced 
in 1993 to prohibit smoking in seven types of public areas $^{12}$ and is periodically amended to include more public areas. By 2015, a total of 38 types of public areas have been gazetted as smoke-free areas. ${ }^{13}$ This regulation is in line with the provisions of article 8 of the Framework Convention on Tobacco Control (FCTC) which was ratified by the Malaysian government in December 2005. The FCTC encourages signatory countries to provide universal measures to protect non-smokers from SHS exposure and to ensure at least $90 \%$ of their population are protected from SHS exposure through smoke-free policies or laws. ${ }^{14}$ However, public support is an important prerequisite element in securing and enforcing effective smoke-free laws. ${ }^{15}$ In a democratic nation like Malaysia, public support is particularly important in facilitating the process of ratifying smoke-free legislations and regulations as well as favouring the acceptance and compliance to such legislations or regulations. Furthermore, public support for smoke-free policy could conceivably favour the enactment of other tobacco control measures such as raising of tobacco taxes, tightening of restrictions on tobacco marketing and expanding smoke-free policy to more controversial domains such as in outdoor areas. ${ }^{16}$

Studies in the Western and Asian regions found that public support for smoke-free policies increased after implementation of smoke-free policies, ${ }^{17-19}$ and its associated factors were working in a smoke-free environment $^{171820}$ and having knowledge on the health hazards of SHS ${ }^{19} 21$ In addition, Borland et al, who investigated the level of support in smoking bans in four countries (UK, USA, Canada and Australia), reported that existence of laws banning smoking, low cigarette consumption and older age ${ }^{21}$ was associated with support for smoke-free policy. Furthermore, Lam et $a l^{22}$ had also reported that non-smokers and the public who were annoyed by exposure to SHS in Hong Kong were more likely to support the legislation of smoke-free policy in public areas.

In Malaysia, there have been only a few studies on the level of support for smoke-free policies since 2000, and these studies were subject to some limitations. Yong and his co-workers, ${ }^{23}$ who analysed baseline data from the International Tobacco Control Southeast Asia Survey in 2005 , reported that $82 \%$ of adult smokers in Malaysia supported the implementation of legally mandated smoke-free areas in air-conditioned venues such as restaurants, coffee houses, karaoke centres and bars. In a longitudinal study that evaluated the efficacy of the smoke-free policy in Malacca, a state located in the southern region of Malaysia, $70 \%$ of the respondents were satisfied with the enactment of the smoke-free policy. ${ }^{24}$ Support was even higher in Penang, a state located in the northern region of Malaysia, where $90.9 \%$ of the public supported the gazetting of the Georgetown World Heritage Site in Penang as a smoke-free zone. ${ }^{25}$ However, the investigators found that respondents of older age, Chinese descent and had poor health consciousness regarding smoking and passive smoking were less likely to support smoke-free policies. ${ }^{25}$ In contrast, Yassin et al had also revealed that non-smokers, those having SHS-related symptoms such as coughing and headache were more likely to support a smoke-free campus. ${ }^{26}$ Nonetheless, despite the availability of local findings, these findings need to be interpreted with cautions. These previous findings could not be generalised to the Malaysian population since the respondents were either totally smokers, ${ }^{23}$ residents or visitors in the study state ${ }^{2425}$ or staff at the respective healthcare training centre or campus. ${ }^{26}$ Therefore, the aim of this study is to investigate the prevalence of support for smoke-free policies in the workplace and in various public domains which are either totally smoking-restricted, partially smoking-restricted or non-restricted, and to determine its associated factors, among a representative sample of Malaysian adults aged 15 years and above. The elucidation of the level of support for smoke-free policies and its associated factors among the Malaysian population could enable the formulation of appropriate measures to establish smoke-free policies, thereby reducing SHS exposure and ultimately reducing the morbidity and mortality attributable to SHS-related diseases.

\section{Methodology}

Data were derived from the GATS-M, a nationwide cross-sectional study conducted from October 2011 to January 2012 which targeted non-institutionalised residents (not hospitalised or residing in an assisted living facility/nursing home, military base, group quarters or prison). The survey employed a multistage proportionate-to-size sampling method to select a representative sample of the Malaysian population aged 15 years and above. The first stage entailed the division of 14 states and 3 federal territories into urban and rural area followed by a random selection of a total of 426 enumeration blocks (EBs; 222 from urban areas and 204 from rural areas) via proportionate-to-population-size approach, and these EBs constituted the primary sampling units. The EBs are artificial geographical areas created by the Department of Statistics, Malaysia based on the 2010 population census, and each of it consists of 80-120 living quarters (LQs). The LQs constituted the secondary sampling unit whereby one household member aged 15 years and above was selected from each selected LQs via simple random sampling using random numbers generated from handheld computers. The final sample size of 5112 was determined based on the standard GATS protocol, at least 4000 respondents (2000 males and 2000 females; with 2000 adults each from urban and rural areas) were required. As a result, the final sample size for GATS-M was 5112 after upward adjustment for potential ineligibility and non-response. The details of the sampling strategy are illustrated in figure 1.

Data were collected via face-to-face interview of the selected respondents by trained research assistants.

The study instrument for the present study was adopted from the GATS and was backward and forward translated by a panel of content and language experts. Then, the translated questionnaire was pilot-tested in both urban 


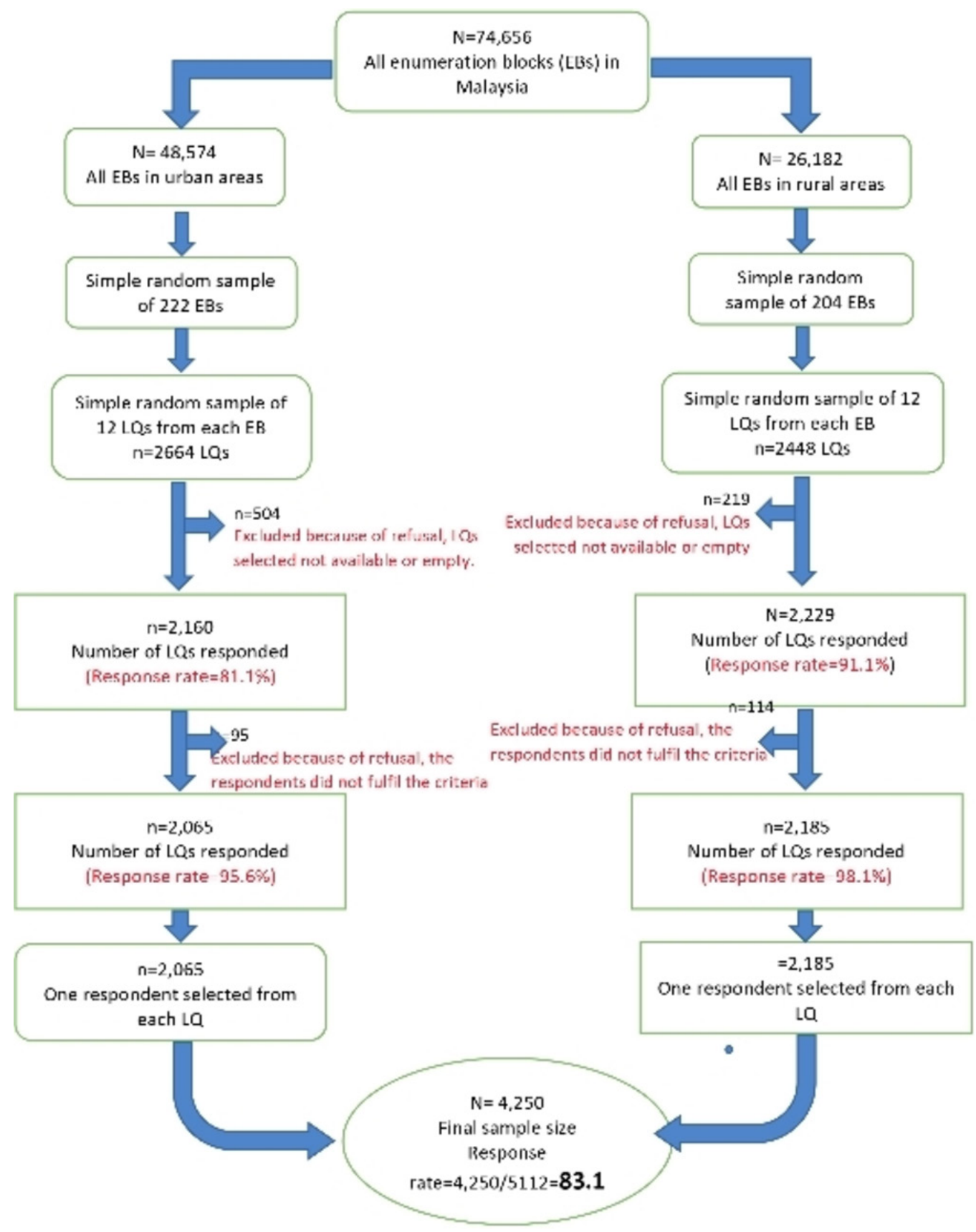

Figure 1 Sampling process for Global Adult Tobacco Survey, Malaysia. LQ, living quarter.

and rural areas in March 2016 among 120 adult respondents who were equally distributed by gender, smoking status and age group, in order to establish face validity. The final questionnaire consisted of eight components: sociodemographic background, smoking status, type of tobacco product used, exposure to SHS (at home, in the workplace and in several public domains), expenditure on tobacco products, knowledge on health impact of smoking and SHS, intention to quit, exposure to advertisement of tobacco product and attitude and behaviour related to smoking.

\section{Measures}

The dependent variable was support for smoke-free policy at a number of public domains of concern. It was assessed by the question 'Do you think smoking should or should not be allowed in these buildings? (a) workplaces, (b) restaurants, (c) bars, (d) hotels, (e) casinos, (f) discos, (g) karaoke centers, (h) public transport terminals, (i) shopping centers.' Only respondents who answered, 'should be allowed', 'should not be allowed' or 'don't know' were included in the analysis while those who chose 'refused to answer' were excluded from the analysis. Also, respondents who answered, 'don't know' and 'should be allowed' were collapsed into a single category to avoid overestimation of level of support for a smoke-free policy.

Independent variables were smoking status, smoking policy at workplace and knowledge on the health hazards 
of SHS and sociodemographic variables. Smoking status was determined by one item, 'Do you currently smoke?' Respondents who answered 'yes, daily' or 'yes, but not daily' were categorised as 'current smoker', whereas those who answered 'no, not at all' were classified as 'non-smoker'. Smoking policy as perceived by the respondents was measured using the item 'Which of the following best describes the indoor smoking policy where you work?' The response options 'smoking is allowed only in some indoor areas' or 'smoking is not allowed in any indoor areas' were combined and considered as 'having smoking policy at workplace', while 'smoking is allowed anywhere' and 'no policy' were combined into the category of 'no smoking policy at workplace'.

Knowledge and beliefs regarding SHS were assessed using three items: 'Based on what you know or believe, does breathing other people's smoke cause the following illness? (a) Heart disease in adults, (b) Lung disease in children, and (c) Lung cancer among adults', with the choices of 'Yes', 'No', 'Don't Know' and 'Refused to answer'. Each 'Yes' response was assigned a value of 1 , and each 'No' or 'Don't know' was assigned a value of 0 . Because there was a total of three questions, the maximum value score was 3 (complete knowledge) and the minimum was 0 (no knowledge). Sociodemographic background consisted of gender, ethnicity (Malay, Chinese, Indian, Others), educational attainment (no formal education, primary education, secondary education and tertiary education), age group (15-24 years old, 25-44 years old, 45-64 years old, 65+ years old), locality (urban, rural), marital status (single, married, widow/widower/separated) and income level. Income level was measured using the wealth index which is a proxy measure for respondent income level. It was constructed using principal component analysis, with information on household ownership of assets such as electricity, flush toilet, fixed phone line, cell phone, television, radio, refrigerator, car, scooter/motorcycle and washing machine. Respondents were then divided into quintiles based on the wealth index, from quintile 1 (lowest income category) to quintile 5 (highest income category).

\section{Statistical analysis}

Data were cleaned prior to analysis and weighted, taking account of the survey sampling design, non-response rate and sociodemographic characteristics (gender, residential area, age group, educational attainment and ethnicity) of the Malaysian population based on the 2010 national population and housing census. Descriptive statistics were used to summarise the sociodemographic characteristics of the respondents, whereas cross-tabulation and $\chi^{2}$ analysis were used to describe variations in smoking status and its association with support for smokefree policy in various public domains. Subsequently, multiple logistic regression was used to determine if associations exist between support for smoke-free policy at public domains of concern, sociodemographic characteristics, knowledge on the health impact of SHS, status of smoking and smoking policy in workplaces. Benjamini and Hochberg procedure was performed to reduce the false discovery rate caused by multiple comparison or testing, that is from fitting more than one model (a total of nine models which corresponded to the total number of public domains of concern) to the data and performing multiple testing within a single multiple logistic regression model (inclusion of a total of 11 independent variables). We report $95 \%$ CIs without $p$ values because the large sample size could generate significant results even when statistical differences or associations are small. All analyses accounted for the complex sampling design and survey weights and were carried out using SPSS V.20 software $(\mathrm{IBM}){ }^{27}$

\section{Patient and public involvement}

Neither patients nor the public were involved in the formulation of research questions and outcome measures, decision of study design, recruitment and conduct of the study. Study findings in the form of technical report were disseminated to relevant stakeholders and public but not specifically to the respondents.

\section{RESULTS}

\section{Description of study participants}

A total of 4250 respondents participated in the study, yielding a response rate of $83.1 \%(4250 / 5112)$, with $77.5 \%(2065 / 2664)$ and $89.3 \% \quad(n=2185 / 2448)$ from urban and rural areas, respectively (data not shown). The weighted proportion of respondents by gender were $51.2 \%$ male and $48.8 \%$ female. The majority of respondents attained primary $(30.8 \%$, 95\% CI: $28.7 \%$ to $32.8 \%)$ and secondary ( $46.6 \%, 95 \%$ CI: $44.4 \%$ to $48.7 \%$ ) education. The ethnic distribution of the respondents resembled that of the general Malaysian population $(58.9 \%$ Malays, $18.6 \%$ Chinese, $9.4 \%$ Indians and $13.2 \%$ others). The prevalence of smoking among Malaysian adults was 23.3\% (data not shown). Males, age between 25 and 44 years or with secondary or lower level of education had significantly higher prevalence of smoking compared with their corresponding counterparts (table 1).

In terms of knowledge on the health impact of SHS, more than $90.0 \%$ of adults were aware of the health hazards of SHS such as causing serious illnesses among non-smokers, heart disease in adults and children as well as lung cancer in adults. Of note, the proportion of non-smokers who perceived the negative impact of SHS on non-smokers (94.5\%, 95\% CI: $93.2 \%$ to $95.5 \%)$ and heart disease in children $(95.6 \%, 95 \%$ CI: $94.5 \%$ to $96.4 \%)$ were significantly higher than among smokers (table 2).

\section{Support for smoke-free policy}

Most of the respondents supported a policy of smoke-free shopping centres $(94.4 \%)$, workplaces $(90.4 \%)$, public transport terminals (85.2\%) and restaurants $(83.5 \%)$. However, the level of support was relatively lower for 


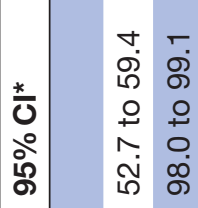 \\ ๑) \\ م \\ 요의 우 \\ సิ \\ ก \\ ن. \\ \begin{tabular}{ccccc}
$\infty$ & 1 & $\infty$ & $\infty$ \\
0 & 0 & 0 & 0 \\
\hline
\end{tabular} \\ 1
0 \\ 穴}

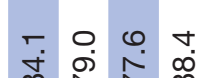

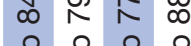

ก $\stackrel{\infty}{\infty} \infty$

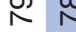

우웅

com

穴

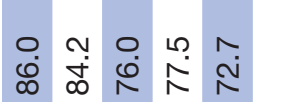

$\circ$ 의 0 인

m $05 \div$

穴

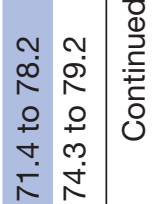

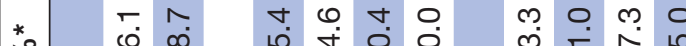

ஃ மீ

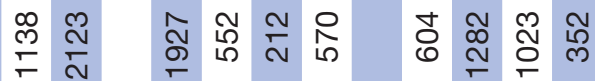

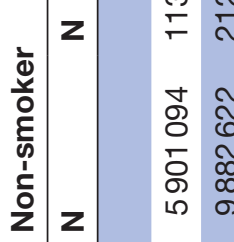

* ชั กั

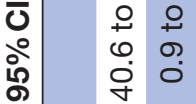

* $\stackrel{\text { ஸे }}{\circ} \stackrel{\wp}{\leftarrow}$

8.

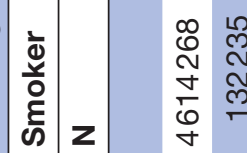

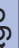

* ஸึ่

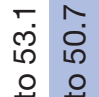

$\therefore$ के

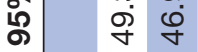

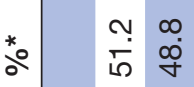

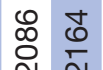

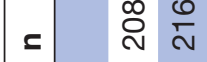

đิ

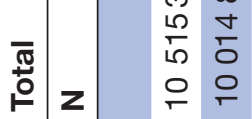

ભ

$\frac{1}{5} \infty$

ํำ

앋ㄷำ

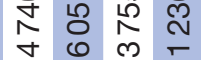

๓. เก ๑

సั

오오 오

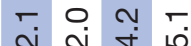

กับ $\stackrel{\leftarrow}{\leftarrow}$

क)

กิ ले ผ

+ 우우

0 ᄃ

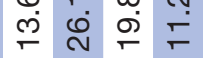

๑ $\forall 0$

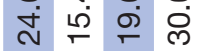

N. O N

ஸ் ลั่

ర্

당

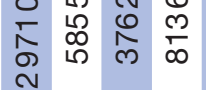

守守 辛

$\infty$ i

辛으

0.0

ชิ่

우우 오 우

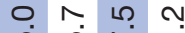

绐

๑)

ஸึ

ヘิ.

忿

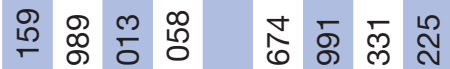

ભ $\infty$ ని

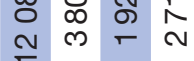

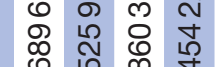

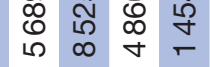

@ู

$\stackrel{1}{n}$

不去

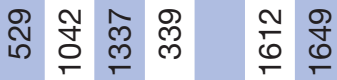

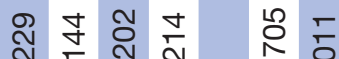

萬

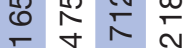

ก ด

ำ ล

우요 우 우

0 우 $\nabla 0$

เ่ ลั่

ก.

के

ลิำ

ᄃू

\&

\& ल्ल

₹

จ

ค่

+2 웅

ก

ลั่

ก.

ลั่

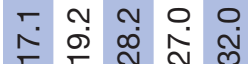

일

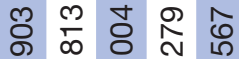

จ $m$ N

둥

సे ले ले ले ले

우우우

$0 . \infty$ L $m$

守占 $\stackrel{\dot{\sim}}{\sim} \stackrel{\text { N }}{\text { N }}$

חై

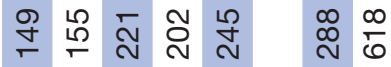

$\infty \frac{\infty}{\infty}$

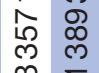

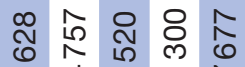

i⿱

$\frac{1}{0} \underset{0}{\sim}$

5

จ. $\infty$ 人. ค

F लें ঐं

लू

아웅ㅇ

の $\wedge$ ○

$\infty \stackrel{\infty}{\sim} \dot{f}$

우

0 ナ

टं

ᄃ.

-

ลิ ลิ

$0-1000$

लำ ำ ำ

웅ㅇㅇㅇㅇ

a 0 a 00

ஸे

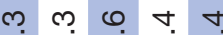

ลें ले เి

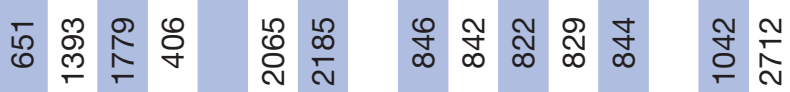

○ స్లి

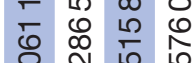

ก 0 ป

ก

要 吕古孚

คै ల్

న

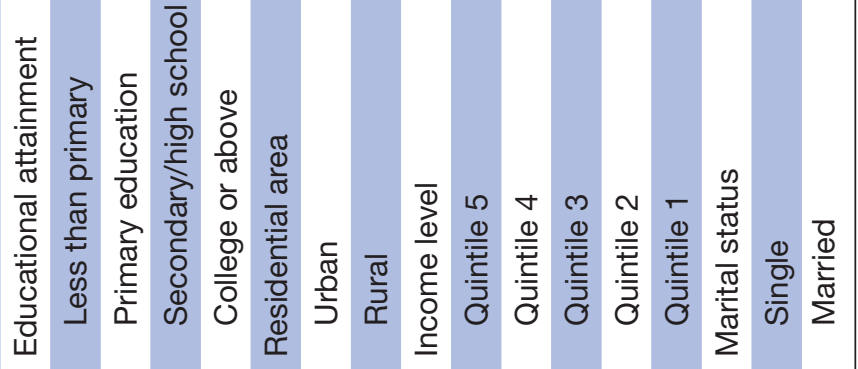

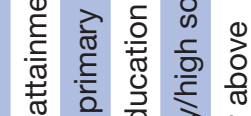

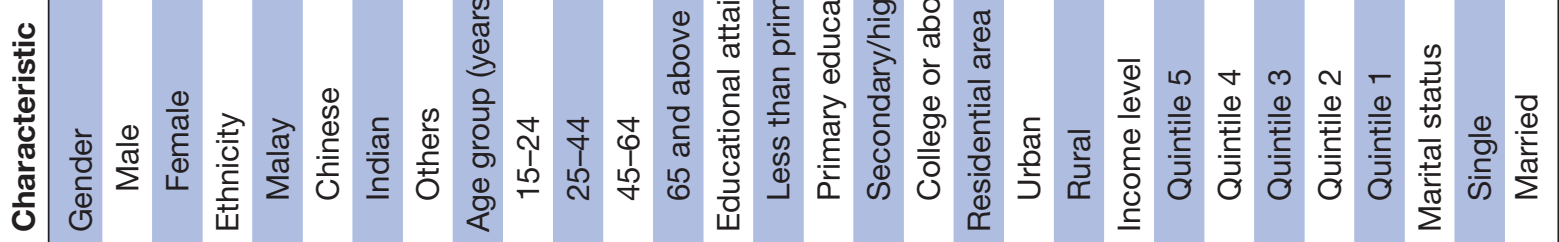




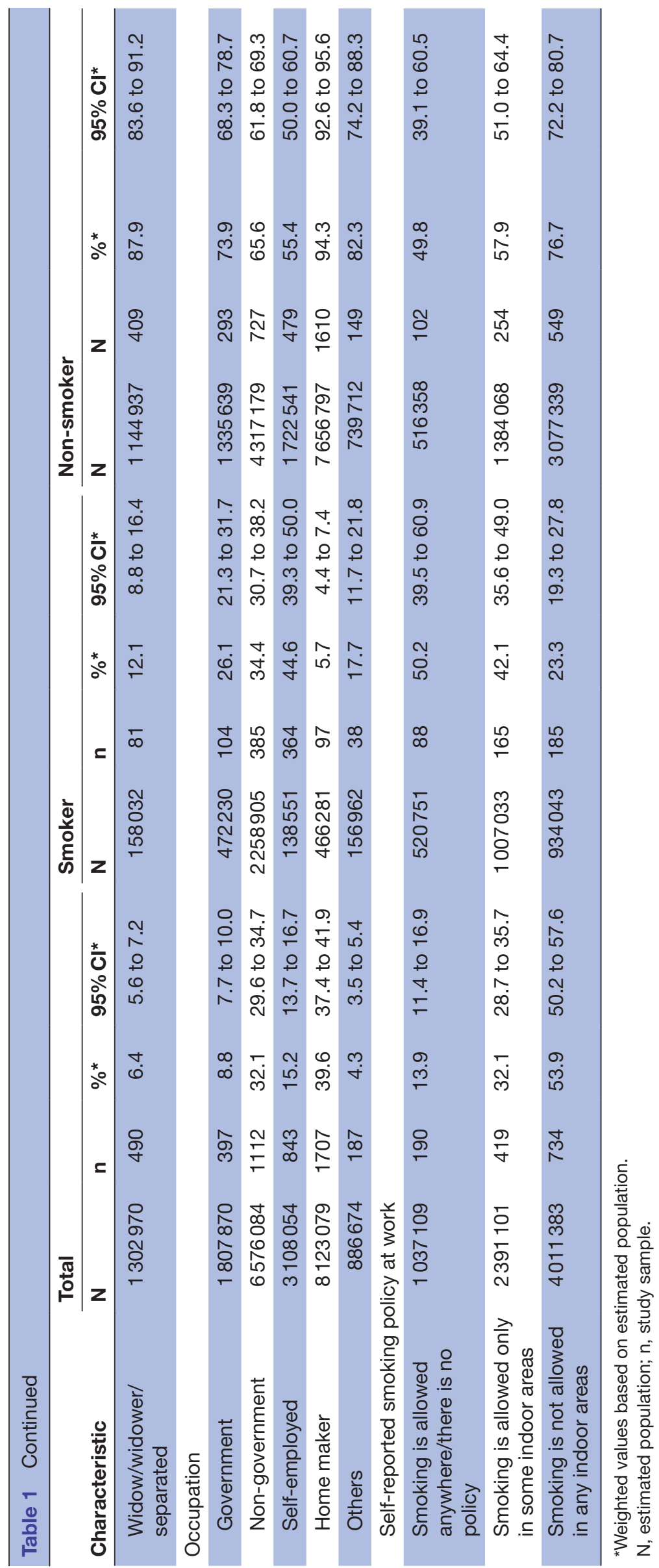


smoke-free bars $(43.9 \%)$, casinos $(40.0 \%)$ and discos $(37.8 \%)$. Overall, non-smokers were significantly more supportive towards smoke-free policies than current smokers, for all public domains, with the highest proportion for smoke-free policy in shopping centres $(95.0 \%)$ and workplaces $(92.4 \%)$ (table 3 ).

\section{Support for smoke-free setting and its sociodemographic predictors \\ Support for smoke-free workplaces}

The odds for non-smokers to support smoke-free workplaces was more than twice as high as smokers (AOR: 2.09, $95 \%$ CI: 1.04 to 4.21 ). In addition, those working in workplaces with total or partial smoking restriction were 14 times (AOR: 14.94, 95\% CI: 6.44 to 34.64) and 3 times (AOR: 2.96, 95\% CI: 1.38 to 6.35 ) more likely to support smoke-free policy at workplaces, respectively. However, better knowledge on the health hazards of SHS (score $=0$, AOR: $0.37,95 \%$ CI: 0.08 to 1.80 ; score $=1$, AOR: 3.12, $95 \%$ CI: 0.74 to 0.13 .37 ; score $=3$ as reference group) as well as sociodemographic factors were not found to be associated with support for smoke-free workplaces (table 4).

Support for smoke-free shopping centres, public transport terminals, restaurants and hotels

This study revealed that non-smokers were more supportive of smoke-free shopping centres (AOR 1.81, 95\% CI: 1.07 to 3.08), public transport terminals (AOR 2.13, 95\% CI: 1.50 to 3.01), restaurants (AOR 1.71, 95\% CI: 1.28 to 2.44 ) and hotels (AOR 1.61, 95\% CI: 1.19 to 2.16). However, those with poor knowledge on the health hazards of SHS were found to be less likely to support smoke-free policy at shopping centres (AOR $0.22,95 \% \mathrm{CI}: 0.13$ to 0.37 ), public transport terminals (AOR 0.36, 95\% CI: 0.23 to 0.56 ) and hotels (AOR 0.55, $95 \%$ CI: 0.38 to 0.81 ). Similarly, respondents who attained less than primary education or were of ethnic minority were less likely to support smoke-free policies at shopping centres, public transport terminals and hotels (table 4).

Support for smoke-free bars, casinos, discos and karaoke centres Smoking status and ethnicity were significant determinants support for smoke-free place (SFP) in the multiple logistic regression analysis. The odds of supporting smoke-free policy at entertainment premises (bars, AOR 1.55, $95 \%$ CI: 1.21 to 1.99 ; casinos, AOR $1.95,95 \%$ CI: 1.50 to 1.53 ; discos, AOR 1.91, 95\% CI: 1.51 to 2.43; and karaoke centres, AOR 1.86, 95\% CI: 1.48 to 2.34) were more than twice as high among non-smokers compared with smokers. The study also revealed that the odds of supporting a smoke-free policy at these domains were significantly higher among Malays or ethnic minorities as compared with the Chinese. However, knowledge on the harmfulness of SHS and sociodemographic variables was not associated with support for smoke-free policy at these domains (table 4). 


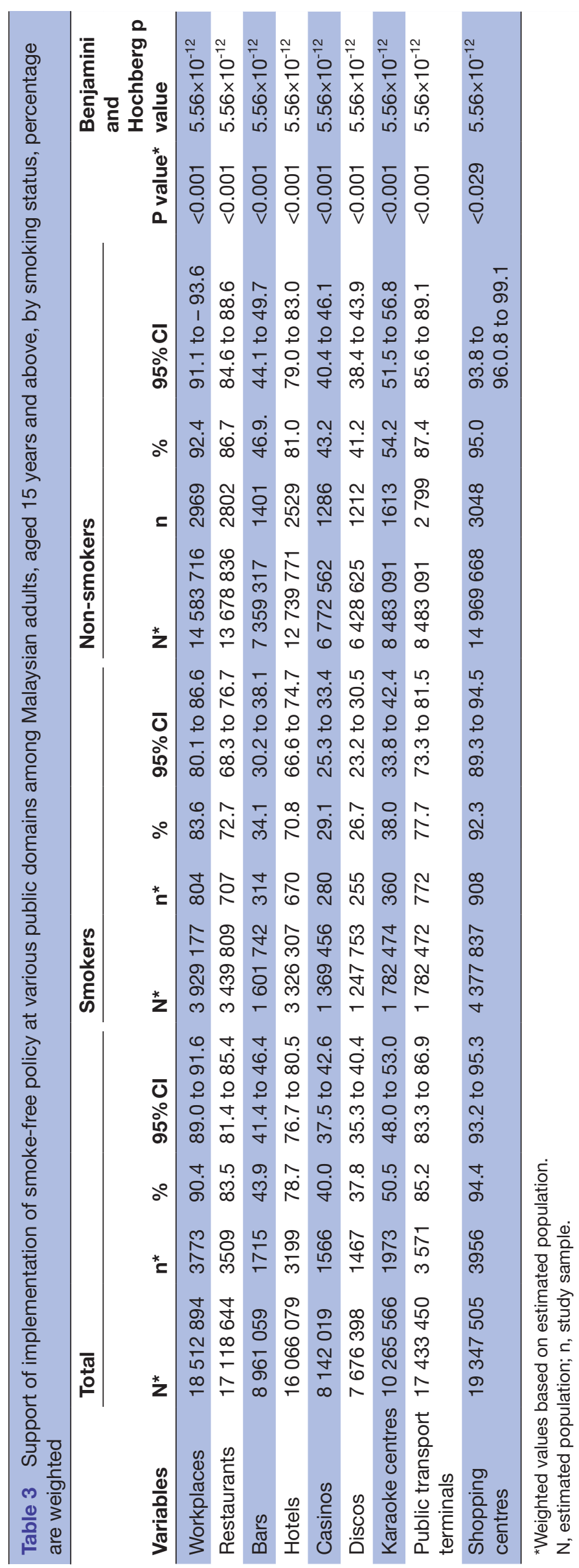




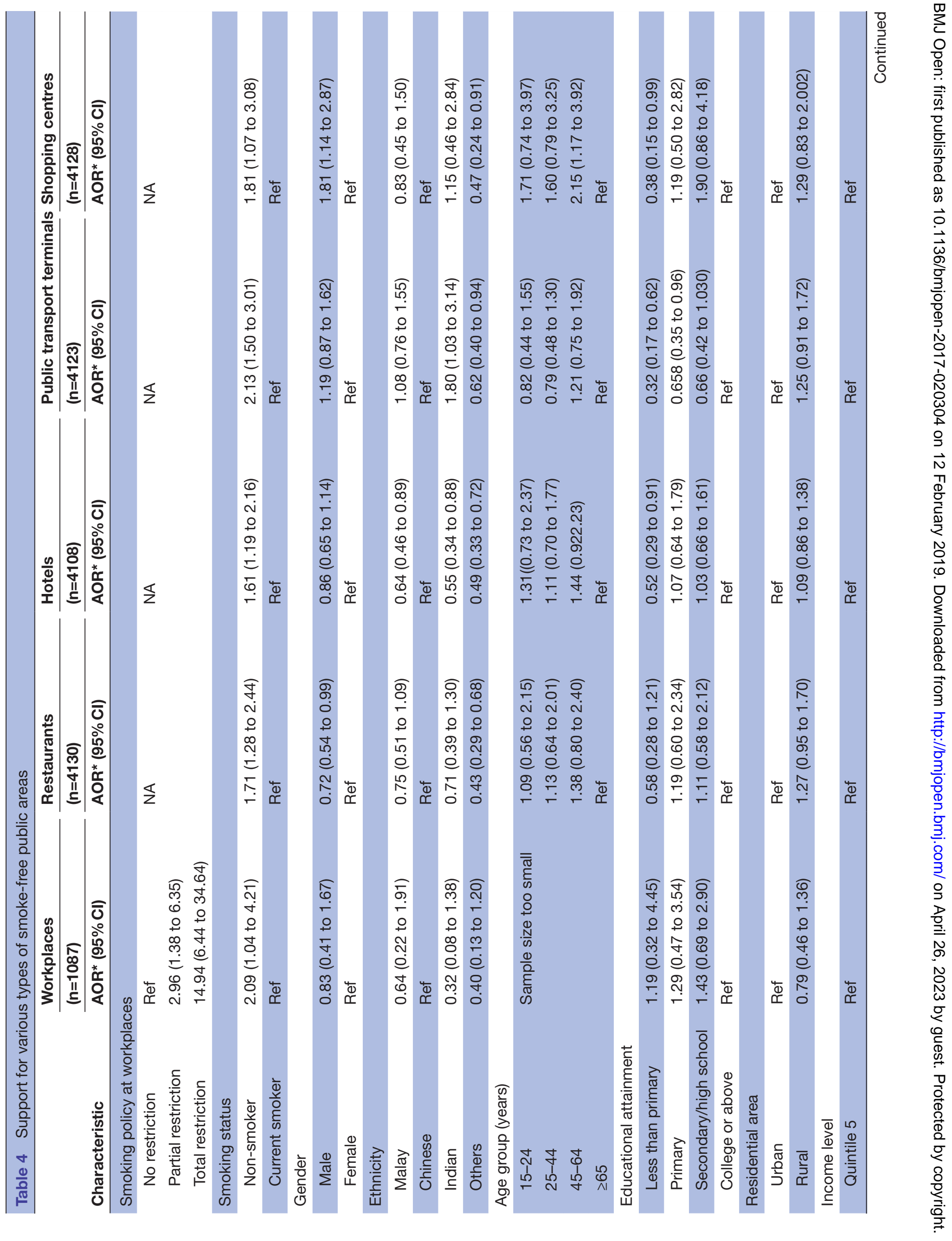




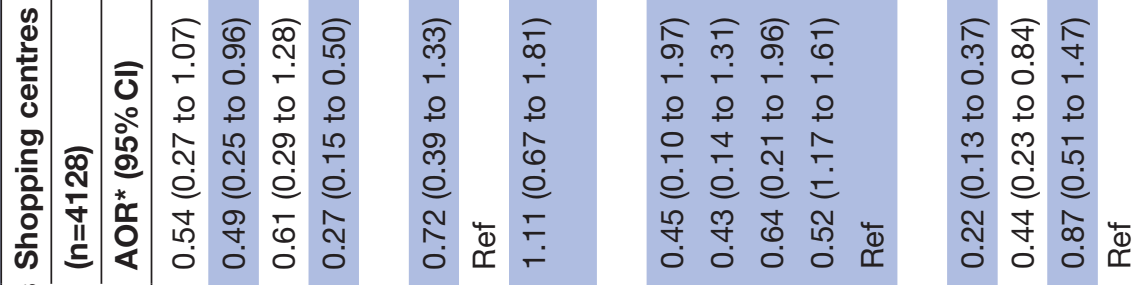

$\frac{0}{\pi}$

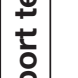

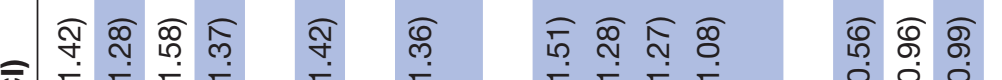

তิ

Г̄

요요

ॠ

ט.

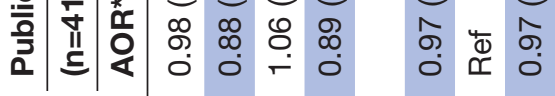

N N N

อ อ อ อ

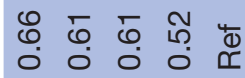

N

อ อ อ

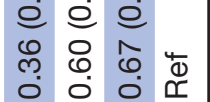

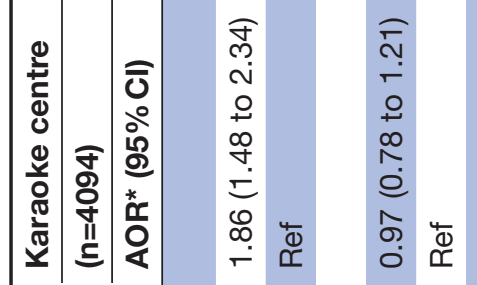

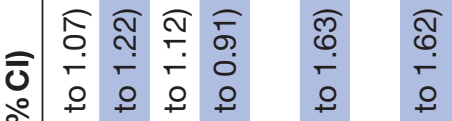

สิ

ง ले ñ

웅ㅇㅇㅇㅇ

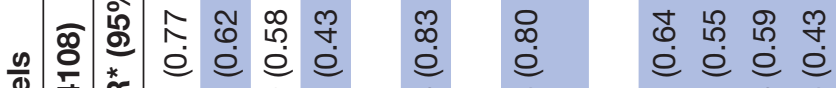

लै

ธิธ ธิธ

० $\div$

우오 웅

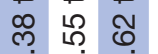

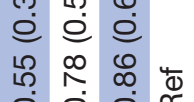

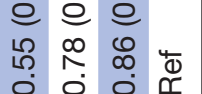

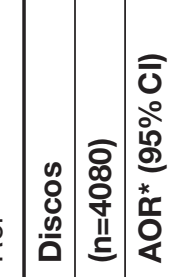

กิ

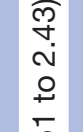

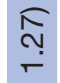

$+$

๙

อ

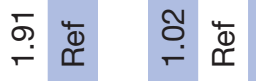

ชุ ชิ ণิษ

두요

7 108

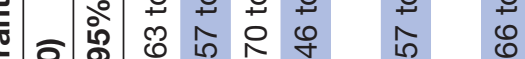

స

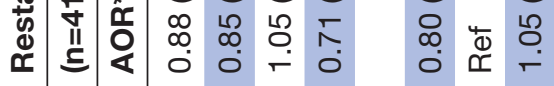

फे ल ले ले

อ 巳 巳 อ

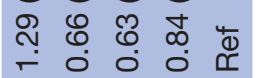

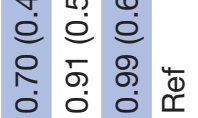

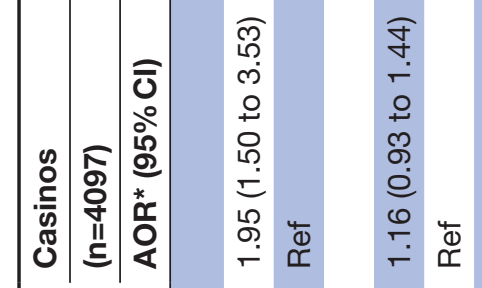

○ิ

웅

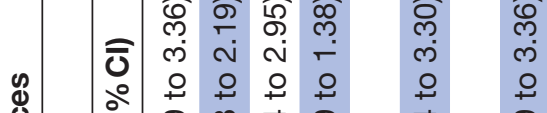

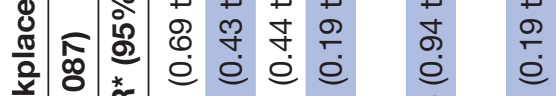

䓂

$\stackrel{N}{n}$

क $\overline{\bar{\sigma}}$

$\infty$ 辛

ஸे

등 


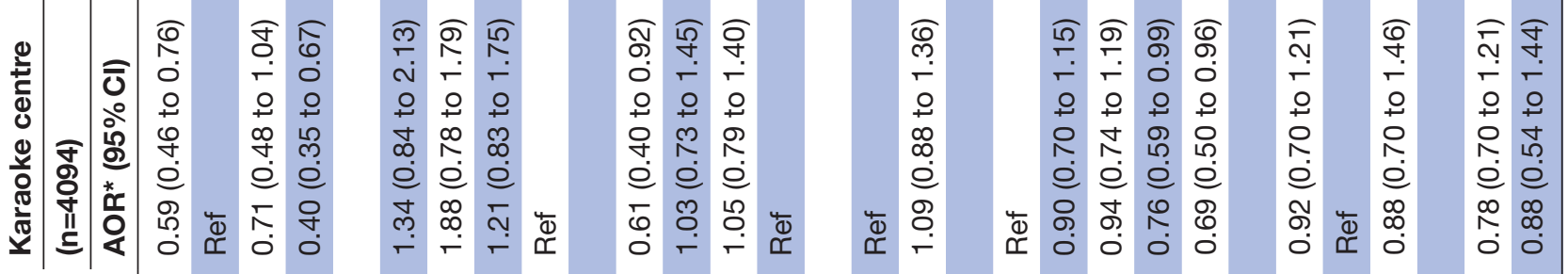

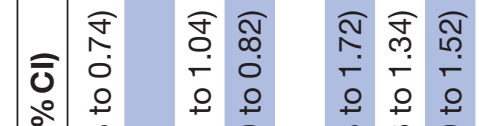

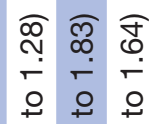
$\frac{\infty}{\stackrel{\infty}{\circ}}$

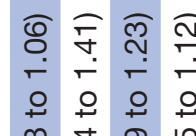

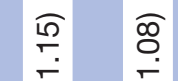
बृ
싱 $\infty$
\%
¿ 巳 ¿
ก
당
둥

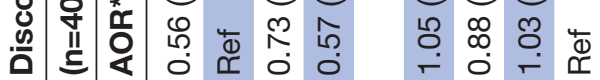

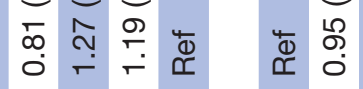

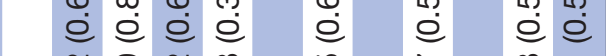
ชి เก
赵

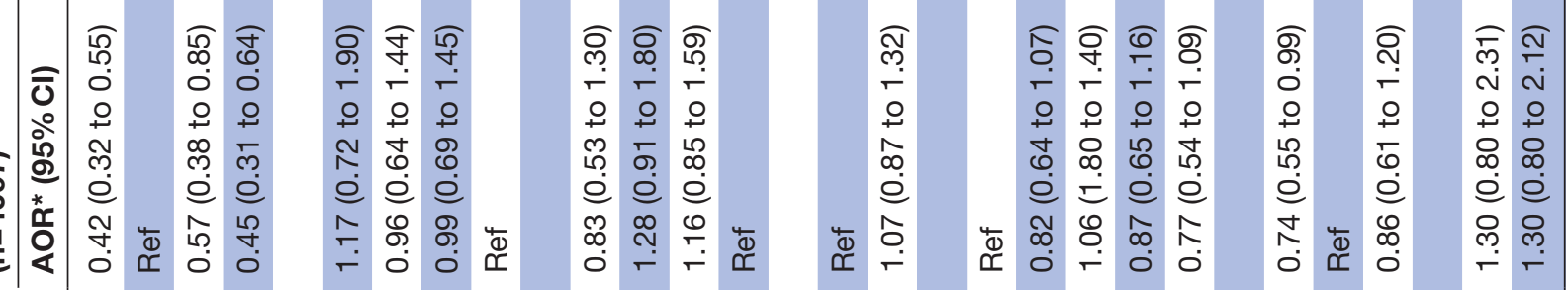

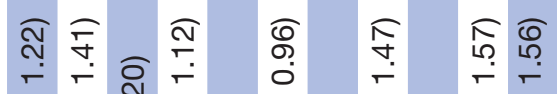

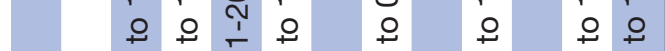

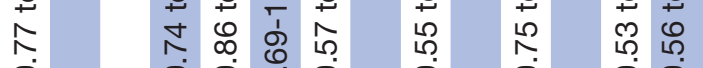

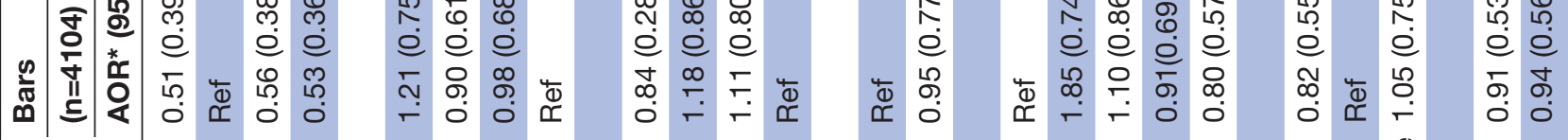




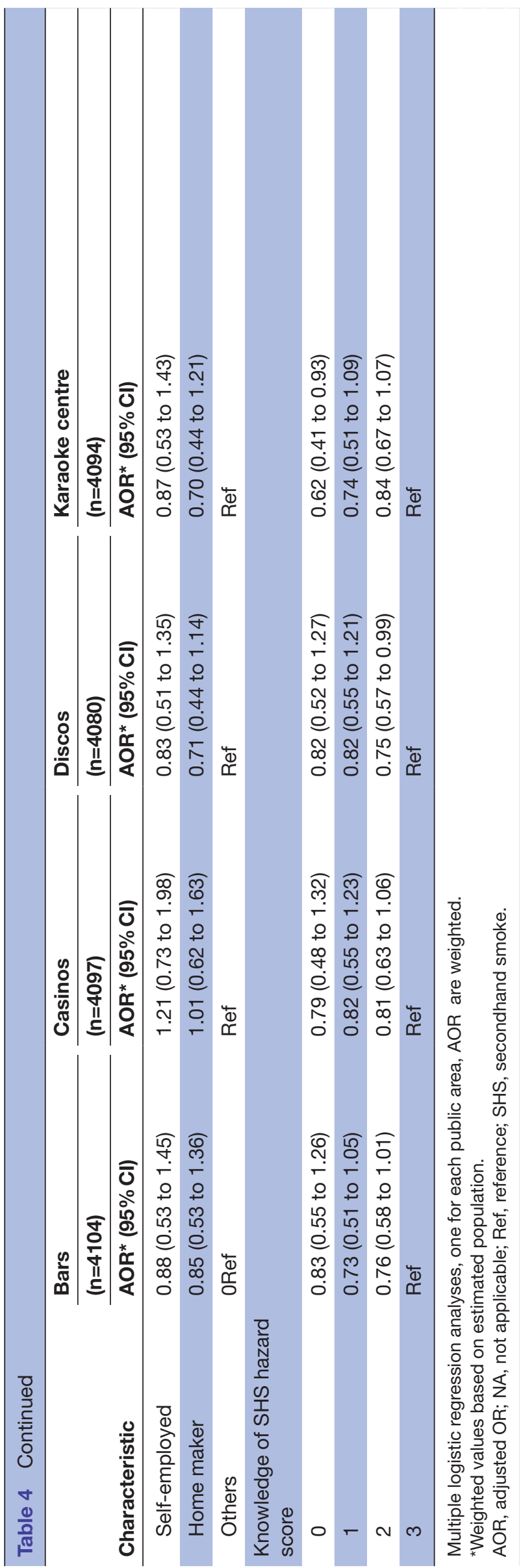

\section{DISCUSSION}

This study examined support for smoke-free policy among a nationally representative sample of adults aged 15 years and above, the first such study in Malaysia. The results showed that more than half $(67.2 \%)$ of the respondents supported a total smoking ban at various public domains, with a higher level of support among the non-smokers. The proportion of support is almost similar to the MBAR survey in Malacca ${ }^{24}$ but was nearly $24 \%$ lower $(90.9 \%)$ than in a recent local study by Rashid and co-workers in Penang. ${ }^{25}$ It is also lower than the rates reported in Uruguay (82\%), ${ }^{10}$ Ashanti region of Ghana $(97 \%)^{28}$ and Taiwan $(91.4 \%) .^{29}$ Yang and colleagues as well as Chapman and co-workers had also reported that $82 \%$ of Chinese urban residents ${ }^{30}$ and $81 \%$ of Australian restaurant workers ${ }^{31}$ favoured a ban on smoking in public places, respectively. These comparatively higher levels of support may be due to extensive health promotion campaigns to increase awareness on the negative impact of SHS on health as well as regular extensive enforcement by relevant authorities in those countries. However, these results need to be interpreted with caution in view of the differences in study localities sociodemographic background and other contributing factors between studies. For instance, Rashid et al who had only investigated support for smoke-free policy within a specific domain, the Unesco heritage areas in Penang could potentially report a higher level of support as compared with the present study which had involved more public domains. In addition, since most of the respondents in the Penang study were Chinese and consisted mostly of clients, customers, patrons or tourists, ${ }^{25}$ the level support for smoke-free policy could have been overestimated as the Chinese were more likely to disapprove of smoking. ${ }^{6}{ }^{32-34}$ Furthermore, clients, customers and tourists who may prefer more comfortable and cosy environments such as a smoke-free area were perceived to be more likely to support smoke-free policy.

Nonetheless, more than $90 \%$ of the respondents perceived that smoking should not be permitted in shopping centres and workplaces, and almost $80 \%$ supported a total ban on smoking in public transport terminals and hotels. However, these levels were lower than reported by Kegler $e t a l^{35}$ among government employees in six cities in China on the levels of support for smoking bans in bars, We postulate that this could be due to religious and cultural factors, in that visiting premises such as casinos and discotheques are deemed inappropriate by some segments of the population in this country. These findings might also be explained by the social control theory, ${ }^{36}$ whereby the internalisation of religion motivates people to follow the tenets of their religion and therefore might influence their support for smoke-free policy in different settings. Some studies have reported that respondents with different religious beliefs behaved differently with regards to support for smoke-free-policy. ${ }^{37-40}$ Another plausible reason is the 'not in my backyard' (NIMBY) mentality. Respondents who never or rarely patronise 
these settings are more likely to be indifferent to regulations or policies to be enforced at those localities. Nonetheless, future studies to affirm such associations are strongly recommended.

In the present study, it is worth noting that support for total smoking restriction was higher for areas that have already been gazetted as totally (shopping centres) or partially (public transport terminals) smoke-free under the CTPR 2014 compared with areas that have yet to be gazetted such as bars, casinos, discos and karaoke centres. Similar findings were observed among adults in Ireland, ${ }^{17}$ where the level of support increased from $43 \%$ to $67 \%$, $45 \%$ to $77 \%$ and $13 \%$ to $46 \%$ for smoke-free policy at workplaces, restaurants and bars/pubs, respectively, after a year of implementation of the smoke-free policy in those domains. A study in Michigan demonstrated that level of support for smoke-free restaurants rose from $37.5 \%$ in 1992 to $59.8 \%$ in 1999 after the enactment. ${ }^{41}$ Similar findings were also reported by Thrasher $e t a t^{42}$ in their study among adults in Uruguay and Mexico. We hypothesise that increasing support in previous studies as well as the higher level of support in gazetted smoke-free areas in the present study could be attributed to first, public appreciation of the beneficial impacts of the smoke-free policy such as reduced SHS exposure and denormalisation of smoking, ${ }^{4344}$ and second, to normative beliefs. ${ }^{45}$ In collectivist communities, that is prevalent in the Malaysian population, the social values and opinions of the community takes precedence over the individual, thus people are more likely to support smoke-free policies if smoking is disapproved by the community. The findings of this study contribute to the body of literature on the effectiveness of smoke-free policies. Health authorities should initiate necessary proactive steps to create and gazette more smoke-free areas in the country, as proposed by the provision under the article 8 of the FCTC. ${ }^{14}$

Respondents who worked at total or partially smokefree workplace were more likely to support smoke-free policy at workplace which is in line with findings from a longitudinal study among health workers in France. ${ }^{46}$ The goal framing theory by Lindenberg $e t a l^{47}$ posits that individuals tend to follow the regulations at their place of work due to hedonic and normative motivations. For example, employees will attempt to avoid bigotry by their superior or peers for not following the rules or regulations stipulated in their workplaces (hedonic). Besides, individuals tend to experience a sense of belonging to the institutions or locations where they work, and the desire to be similar to others can drive them to follow the rules and regulation at their workplaces (normative).

In the present study, more than $90 \%$ of the smokers perceived that SHS causes lung cancer in adults and children which is higher than the figures reported in other Asian ${ }^{18}$ and Western countries. ${ }^{19}$ This suggests that health promotional activities pertaining to the health hazards of SHS carried out by the local health authorities over the past decades were effective. In addition, the present study also demonstrates that knowledge on the adverse health effects of SHS is positively associated with support for smoke-free policy at hotels, public transport terminals and shopping centres; however, such associations were insignificant at casinos, discos and bars. These findings corroborated those reported by Li et $a l^{18}$ and Kegler et $a l^{35}$ whereby the level of support for SHS policy increased with knowledge score and that level of support for SHS was higher in public domains such as hospital, school and public transportation as compared with entertainment domain such as bar. The lower level of support for SHS policy at entertainment domains such as casinos, discos and bars could be because most respondents in the present study either rarely frequent or are prohibited from patronising such premises due to religious beliefs, and therefore, according to the "NIMBY' theory, they might be less concerned about smoke-free legislation in those areas. Nonetheless, intensive community interventional programmes such as KOSPEN (Komuniti Sihat Perkasa Negara) should be advocated in order to convey the message on the hazardous impact of SHS on health ${ }^{48}$ among Malaysian adults and thus increase support for SHS policy ${ }^{182}$ and denormalise smoking. ${ }^{39}$

As in previous studies, ${ }^{28} 294950$ our study also found stronger support for smoke-free legislation among non-smokers compared with their smoking peers. The lack of support towards smoke-free policy among smokers might be due to several factors. Smokers may perceive smoke-free legislation as a hindrance to smoking in public areas and as such anticipation of future difficulties might reduce their support on smoke-free policies. Second, smokers tend to downplay the health hazards of SHS towards non-smokers and in order to rationalise their smoking behaviour, they tend to adopt positive perceptions of smoking, such as perception of smoking as an individual's right, or of exposure to SHS as less harmful than exposure to vehicle emission. Festinger's cognitive dissonance theory postulates that there is a tendency for humans to seek consistency between their beliefs, perceptions and behaviours, but when inconsistencies occur (the smoker perceives smoking is harmful but still continues to smoke), they will look for an alteration in either their beliefs, perceptions (distorted the negative health impact of SHS into positive ones) or behaviours (quit smoking) to reduce or eliminate dissonance and restore internal consistency. ${ }^{51}$ Since perception is easier to change than behaviour, smokers therefore are more likely to adopt the risk-minimising belief about smoking or SHS and oppose smoke-free legislation.

As for sociodemographic factors, few were found to be significantly associated with support. For instance, males were less likely to support smoke-free policy in restaurants than females. Besides the Malays, other minor ethnicities or those who were single were less likely to support the smoke-free policy in entertainment domains such as bars, casinos, discos and karaoke centres, and these observations can be explained by the 'NIMBY' syndrome as their religious beliefs prohibit them from patronising these types of outlets. Hence, they are less likely to be concerned 
about smoke-free legislation at these places. On the other hand, there were no differences in the level of support for smoke-free policy between age groups, residential areas or occupational categories. However, the associated sociodemographic factors for support in smoke-free policy were quite varied between studies due to differences in the sociodemographic background of the study populations. For instance, Okoli et a $\tilde{l}^{2}$ reported that females, respondents who were married or of higher educational attainment were more likely to support smoke-free policies. On the other hand, women (AOR: 4.04, 95\% CI: 2.84 to $5.74, \mathrm{p}<0.001$ ), rural dwellers (AOR: $2.15,95 \%$ CI: 1.46 to $3.18, \mathrm{p}<0.001)$ and young people $(\mathrm{p}=0.004)$ in Ghana were found to be significantly less likely to support smoke-free policies (AOR: 0.08, 95\% CI: 0.05 to 0.14, $\mathrm{p}<0.001)^{28}$; however, for females, other studies demonstrated otherwise. ${ }^{38-52}$ In terms of age, an International Tobacco Control survey in four countries revealed that people of older age were more supportive of smoke-free policy. ${ }^{19}{ }^{54}$ While, Brownson et a $\hat{p}^{5}$ reported that better educated people or white-collar workers were more likely to support smoking bans than their respective peers. In view of the vast difference in sociodemographic attributes for support in smoke-free legislation, the formulation and implementation of antismoking strategies should be based on the findings from country-specific research but not inferring from other studies.

This study has several limitations. First, a cross-sectional study design was used and therefore cause and effect relationships cannot be deduced from it. Second, under the influence of social norms in their immediate surroundings, the respondents might have over-reported or under-reported their support. Nevertheless, the large sample size and recruitment of a representative sample of smokers and non-smokers that enable generalisation of the findings to the Malaysian adult population should outweigh the limitations.

\section{CONCLUSION}

Smoke-free legislation was well-accepted and supported by Malaysian adults. The level of public knowledge on the health hazards of SHS was positively associated with the level of support for smoke-free policies, particularly in the frequently visited areas such as shopping centres and public transport terminal. More interventional and health educational programmes with a special emphasis on smokers should be conducted on a regular basis to advocate the health hazards of SHS and encourage behavioural changes. The high support in smoke-free legislation indicated promising outcomes in expanding smoke-free zones and gazetting more smoke-free public domains.

Acknowledgements We would like to thank the Director-General of Health Malaysia for his permission to publish this paper. We would also like to thank those who were involved in the study and who assisted in the collection and management of the data for their support and cooperation.
Contributors All authors were responsible and accountable to all part of works related to the study. More specifically, LKH, PS, MY, MF, LMY, LKK, GSM and VY contributed to the conception and design of the study. VY, LKK, MY and MF were responsible for data acquisition and coordination of the study. LKH, CKC and GSM were involved in data management, performed statistical analysis and interpretation of the data. LKH, LHL and TCH contributed substantially to the writing and revising of the manuscript. All authors critically revised the manuscript and gave final approval to the version to be published.

Funding The project was funded by Ministry of Health, Malaysia and Bloomberg Philanthropies.

Competing interests None declared.

Patient consent for publication Obtained.

Ethics approval Medical Research and Ethical Commitee, Ministry of Health, Malaysia.

Provenance and peer review Not commissioned; externally peer reviewed.

Data sharing statement No additional data are available.

Open access This is an open access article distributed in accordance with the Creative Commons Attribution Non Commercial (CC BY-NC 4.0) license, which permits others to distribute, remix, adapt, build upon this work non-commercially, and license their derivative works on different terms, provided the original work is properly cited, appropriate credit is given, any changes made indicated, and the use is non-commercial. See: http://creativecommons.org/licenses/by-nc/4.0/.

\section{REFERENCES}

1. Vineis P, Airoldi L, Veglia F, et al. Environmental tobacco smoke and risk of respiratory cancer and chronic obstructive pulmonary disease in former smokers and never smokers in the EPIC prospective study. BMJ 2005;330:277.

2. Oberg M, Jaakkola MS, Woodward A, et al. Worldwide burden of disease from exposure to second-hand smoke: a retrospective analysis of data from 192 countries. Lancet 2011;377:139-46.

3. Siegel M, Skeer M. Exposure to secondhand smoke and excess lung cancer mortality risk among workers in the " 5 B's": bars, bowling alleys, billiard halls, betting establishments, and bingo parlours. Tob Control 2003;12:333-8.

4. Pitsavos C, Panagiotakos DB, Chrysohoou C, et al. Association between passive cigarette smoking and the risk of developing acute coronary syndromes: the CARDIO2000 study. Heart Vessels 2002;16:127.

5. Iribarren C, Darbinian J, Klatsky AL, et al. Cohort study of exposure to environmental tobacco smoke and risk of first ischemic stroke and transient ischemic attack. Neuroepidemiology 2004;23(1-2):38-44.

6. Institute for Public Health (IPH). Report of the Global Adult Tobacco Survey (GATS) Malaysia. Malaysia: Ministry of Health, 2012.

7. U.S. Department of Health and Human Services. The Health Consequences of Involuntary Exposure to Tobacco Smoke: A Report of the Surgeon General-Executive Summary: U.S. Department of Health and Human Services, Centers for Disease Control and Prevention, Coordinating Center for Health Promotion, National Center for Chronic Disease Prevention and Health Promotion, Office on Smoking and Health, 2006.

8. Callinan JE, Clarke A, Doherty K, et al. Legislative smoking bans for reducing secondhand smoke exposure, smoking prevalence and tobacco consumption. Cochrane Database Syst Rev 2010(4):CD005992.

9. Galán I, Mata N, Estrada C, et al. Impact of the "Tobacco control law" on exposure to environmental tobacco smoke in Spain. BMC Public Health 2007;7:224.

10. Thrasher JF, Swayampakala K, Arillo-Santillán E, et al. Differentia impact of local and federal smoke-free legislation in Mexico: a longitudinal study among adult smokers. Salud Publica Mex 2010;52 Suppl 2(Suppl 2):S244-S253.

11. Raute LJ, Gupta PC, Pednekar MS. Smoking ban and indoor air quality in restaurants in Mumbai, India. Indian J Occup Environ Med 2011;15:68-72.

12. Government of Malaysia. Food act 1993: Control of tobacco product regulations 2004. 2005 http://www.tobaccocontrollaws.org/files/live/ Malaysia/Malaysia\%20-\%20TC\%20Regs\%202004.pdf (Accessed on 15 Oct 2017).

13. Government of Malaysia. Declaration of non-smoking area. 2017 http://www.federalgazette.agc.gov.my/outputp/pub_20170621_ Draf20Perisytiharan\%20kawasan\%20larangan\%20merokok\% 20Terengganu\%202017.pdf (Accessed on 5.9.2017). 
14. WHO. WHO Framework Convention on Tobacco Control. Geneva, 2003. http://whqlibdoc.who.int/ publications/2003/9241591013.pdf. (accessed 26 Jun 2016).

15. World Health Organization. International Agency for Research on Cancer (IARC): Evaluating the effectiveness of smoke-free policies. 13. Lyon, France: Handbooks of Cancer Prevention, 2009. Tobacco Control.

16. Chapman S. Public health advocacy and tobacco control: Making smoking history. Oxford, Blackwell Publishing 2007.

17. Fong GT, Hyland A, Borland R, et al. Reductions in tobacco smoke pollution and increases in support for smoke-free public places following the implementation of comprehensive smoke-free workplace legislation in the Republic of Ireland: findings from the ITC Ireland/UK Survey. Tob Control 2006;15 Suppl 3:iii51-iii58.

18. Li Q, Hyland A, O'Connor R, et al. Support for smoke-free policies among smokers and non-smokers in six cities in China: ITC China Survey. Tob Control 2010;19 Suppl 2(Suppl 2):i40-i46.

19. Borland R, Mullins R, Trotter $\mathrm{L}$, et al. Trends in environmental tobacco smoke restrictions in the home in Victoria, Australia. Tob Control 1999;8:266-71.

20. Wakefield M, Roberts L, Owen N. Trends in prevalence and acceptance of workplace smoking bans among indoor workers in South Australia. Tob Control 1996;5:205-8.

21. Wilson N, Weerasekera D, Blakely $\mathrm{T}$, et al. What is behind smoker support for new smokefree areas? National survey data BMC Public Health 2010;10:498.

22. Lam TH, Janghorbani M, Hedley AJ, et al. Public opinion on smokefree policies in restaurants and predicted effect on patronage in Hong Kong. Tob Control 2002;11:195-200.

23. Yong $\mathrm{HH}$, Foong $\mathrm{K}$, Borland $\mathrm{R}$, et al. Support for and reported compliance among smokers with smoke-free policies in airconditioned hospitality venues in malaysia and thailand: findings from the international tobacco control southeast asia survey. Asia Pac J Public Health 2010:22:98-109.

24. Project M. Smoke free Melaka Policy Promoting evidence base strategy to fight the Global Tobacco Epidemic. Malaysia: Universiti Sains Malaysia, Pulau Pinang, Malaysia, MySihat. University of Waterloo, Waterloo, Ontario, Canada; and Melaka Health Department, 2014.

25. Rashid A, Manan AA, Yahya N, et al. The support for smoke free policy and how it is influenced by tolerance to smoking - experience of a developing country. PLoS One 2014;9:e109429.

26. Yasin SM, Isa MR, Fadzil MA, et al. Support for a campus tobaccofree policy among non-smokers: Findings from a developing Country. Asian Pac J Cancer Prev 2016;17:275-80.

27. Ibm CR. IBM SPSS Statistics for Windows, Version 20.0. Armonk, NY: IBM Corp 2011

28. Owusu-Dabo E, Lewis S, McNeill A, et al. Support for smoke-free policy, and awareness of tobacco health effects and use of smoking cessation therapy in a developing country. BMC Public Health 2011;11:572.

29. Tsai YW, Yen LL, Yang CL, et al. Public opinion regarding earmarked cigarette tax in Taiwan. BMC Public Health 2003:3:42.

30. Yang T, Wu Y, Abdullah AS, et al. Attitudes and behavioral response toward key tobacco control measures from the FCTC among Chinese urban residents. BMC Public Health 2007;7:248.

31. Chapman S, Borland R, Lal A. Has the ban on smoking in New South Wales restaurants worked? A comparison of restaurants in Sydney and Melbourne. Med J Aust 2001;174:512-5.

32. Institute of Public Health, Ministry of Health Malaysia 1996. National Health and Morbidity Survey. 1996;15.Smoking.

33. Institute of Public Health, Ministry of Health Malaysia 2008. The Third National Health and Morbidity Survey- Smoking, 2006.

34. Institute of Public Health, Ministry of Health Malaysia 2011, National Health and Morbidity Survey. 2011;II.
35. Kegler MC, Hua X, Solomon M, et al. Factors associated with support for smoke-free policies among government workers in Six Chinese cities: a cross-sectional study. BMC Public Health 2014;14:1130.

36. Wiatrowski MD, Griswold DB, Roberts MK. Social control theory and delinquency. Am Sociol Rev 1981;46:525-41.

37. Jagodzinski W, Dülmer H. Political Influence of Religion in the Enlarged EU. Paper presented at the 37th World Congress of the International Institute of Sociology. Stockholm, Sweden, 2005.

38. Lim KH, Lim HL, Teh $\mathrm{CH}$, et al. Smoking among school-going adolescents in selected secondary schools in peninsular malaysiafindings from the malaysian adolescent health risk behaviour (MyaHRB) study. Tob Induc Dis 2017;15:9.

39. Sucakli MH, Ozer A, Celik M, et al. Religious officials' knowledge, attitude, and behavior towards smoking and the new tobacco law in Kahramanmaras, Turkey. BMC Public Health 2011;11:602.

40. Yong HH, Hamann SL, Borland R, et al. Adult smokers' perception of the role of religion and religious leadership on smoking and association with quitting: a comparison between Thai Buddhists and Malaysian Muslims. Soc Sci Med 2009;69:1025-31.

41. Brooks DR, Mucci LA. Support for smoke-free restaurants among Massachusetts adults, 1992-1999. Am J Public Health 2001;91:300-3.

42. Thrasher JF, Boado M, Sebrié EM, et al. Smoke-free policies and the social acceptability of smoking in uruguay and mexico: findings from the international tobacco control policy evaluation project. Nicotine Tob Res 2009;11:591-9.

43. Albers AB, Siegel M, Cheng DM, et al. Effect of smoking regulations in local restaurants on smokers' anti-smoking attitudes and quitting behaviors. Tob Control 2007;2007:101-6.

44. Levy DT, Friend K. A framework for evaluating and improving clean indoor air laws. J Public Health Manag Pract 2001;7:87-96.

45. Fishbein M, amp;Ajzen I. Predicting and changing behavior: The reasoned action approach. New York: Psychology Press, 2010.

46. Fathallah N, Maurel-Donnarel E, Baumstarck-Barrau K, et al. Three-year follow-up of attitudes and smoking behaviour among hospital nurses following enactment of France's national smoke-free workplace law. Int J Nurs Stud 2012;49:803-10.

47. Lindenberg S, Steg L, Normative SL. Normative, Gain and Hedonic Goal Frames Guiding Environmental Behavior. J Soc Issues 2007;63:117-37.

48. Lim KH, Mohd Fadhli MY, Rosnah R, et al. Evaluation of Effectiveness of Implementation of "Komuniti Sihat Perkasa Negara" (KOSPEN) Programme in Malaysia- Phase 1. Malaysia: Ministry of Health, 2014.

49. Scollo MM, Winstanley MH. Tobacco in Australia: Facts and issues. Melbourne: Cancer Council Victoria, 2016. www.TobaccolnAustralia. org.au. (accessed 12 Nov 2017).

50. Lazuras L, Rodafinos A, Panagiotakos DB, et al. Support for smokefree policies in a pro-smoking culture: findings from the European survey on tobacco control attitudes and knowledge. Int $J$ Public Health 2009;54:403-8.

51. Cooper. Cognitive Dissonance, Fifty years of a classic theory. London: Sage Publications, 2007.

52. Okoli CT, Pederson A, Rice W. Support for a smoke-free bylaw in parks and on beaches. Health Policy 2013;111:127-34.

53. Rayens MK, Hahn EJ, Langley RE, et al. Public support for smokefree laws in rural communities. Am J Prev Med 2008;34:519-22.

54. Berg CJ, Topuridze M, Maglakelidze N, et al. Reactions to smokefree public policies and smoke-free home policies in the Republic of Georgia: results from a 2014 national survey. Int J Public Health 2016;61:409-16.

55. Brownson RC, Hopkins DP, Wakefield MA. Effects of Smoking Restrictions in the Workplace. Annu Rev Public Health 2002;23:333-48. 